\title{
Using Smartphone Crowdsourcing to Redefine Normal and Febrile Temperatures in Adults: Results from the Feverprints Study
}

\author{
Jonathan S. Hausmann, MD ${ }^{1,2}$, Ron Berna, BS ${ }^{3,4}$, Nitin Gujral, MS, MBA4, Soleh Ayubi, Ph.D., ${ }^{4,5}$, \\ Jared Hawkins, Ph.D. ${ }^{4}$, John S. Brownstein, Ph.D. ${ }^{4}$, and Fatma Dedeoglu, MD ${ }^{7}$ \\ 'Department of Rheumatology, Boston Children's Hospital, Boston, MA, USA; 'Division of Rheumatology, Beth Israel Deaconess Medical Center,

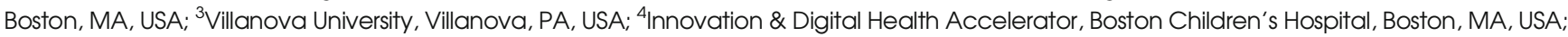 \\ ${ }^{5}$ UnitedHealth Group, Boston, MA, USA.
}

KEY WORDS: smartphone; crowdsourcing; ResearchKit; temperatures; fever.

J Gen Intern Med 33(12):2046-7

DOI: $10.1007 / \mathrm{s} 11606-018-4610-8$

() Society of General Internal Medicine 2018

\section{INTRODUCTION}

Fever is often the first symptom of illness, a common reason for physician visits, and a cause for anxiety in patients, families, and the healthcare team. The most widely used definition of normal $\left(37^{\circ} \mathrm{C}\right)$ and febrile $\left(38^{\circ} \mathrm{C}\right)$ temperatures derive from a single study from 1868 , despite recent research describing lower average and febrile temperatures, with fluctuations based on circadian rhythm and demographics [1-3]. Nevertheless, decisions to admit patients to the hospital, perform invasive procedures, or provide antibiotics are still made using these outdated values. Smartphones and wearable technology may allow us to redefine normal and febrile temperatures for individuals of different demographics and to improve our recognition of febrile illnesses. Researchers can now rapidly recruit large numbers of patients and crowdsource their data through platforms such as ResearchKit (Apple). Whether patientreported data obtained through crowdsourcing conforms to research conducted under controlled conditions is still unknown.

We developed Feverprints, a ResearchKit app, to crowdsource temperature data in health and disease and to test whether this platform produces reliable data.

\section{METHODS}

Participants downloaded Feverprints from Apple's App Store and provided consent. Children and adults living in the USA who owned thermometers were eligible to participate. Surveys assessed demographics, medical and family history, and medications. Participants manually recorded temperatures, associated symptoms, and antipyretic use within Feverprints. The Boston Children's Hospital Institutional Review Board approved this study.

"Normal" temperatures were calculated from asymptomatic, non-medicated patients. As in previous studies [2, 4], we defined

Published online August 13, 2018 "fever" as the 99th percentile of normal temperatures. Group means were calculated by taking the mean of users' mean temperatures, restricting data to temperatures less than the febrile cutoff. Group differences were assessed with $t$ tests. While participants could take their temperature in any body location, we restricted the current analysis to oral temperatures to limit variability; children under 18 years of age were also excluded.

\section{RESULTS}

We collected 5038 oral temperatures from 329 participants from March 2016 to June 2017. Participant characteristics are shown in the Table 1.

The mean "normal" temperature (2792 temperatures from 208 users) was $36.5^{\circ} \mathrm{C}\left(\mathrm{SD}=0.4^{\circ} \mathrm{C}\right)$. The 99 th percentile was $37.5^{\circ} \mathrm{C}$. The average daily temperature trend is shown in Figure 1. Minimum temperature occurred between 3 am and $5 \mathrm{am}\left(\right.$ mean $\left.=36.1^{\circ} \mathrm{C}, \mathrm{SD}=0.3{ }^{\circ} \mathrm{C}\right)$, while maximum temperature occurred between $4 \mathrm{pm}$ and $6 \mathrm{pm}$ (mean $=36.7^{\circ} \mathrm{C}, \mathrm{SD}=$ $\left.0.5^{\circ} \mathrm{C}\right)$. The 99 th percentile also varied from $36.9^{\circ} \mathrm{C}(3 \mathrm{am}-5$ am) to $37.9^{\circ} \mathrm{C}(4 \mathrm{pm}-6 \mathrm{pm})$.

Male temperature $\left(\right.$ mean $=36.5{ }^{\circ} \mathrm{C}, \mathrm{SD}=0.4{ }^{\circ} \mathrm{C}$ ) was lower than female temperature $\left(\right.$ mean $=36.6{ }^{\circ} \mathrm{C}, \mathrm{SD}=$ $\left.0.4{ }^{\circ} \mathrm{C}, p=0.05\right)$. There was a weak but statistically

Table 1 Participant Characteristics $(n=329)$

\begin{tabular}{ll}
\hline \hline Characteristics & Number (\%) \\
\hline Gender & \\
Male & $122(37.1 \%)$ \\
Female & $190(57.8 \%)$ \\
Chose not to respond & $17(5.2 \%)$ \\
Age & \\
18-30 & $80(24.3 \%)$ \\
$31-45$ & $116(29.7 \%)$ \\
$46-60$ & $80(24.3 \%)$ \\
61+ & $60(18.2 \%)$ \\
Chose not to respond & $1(0.003 \%)$ \\
Ethnicity & $272(82.7 \%)$ \\
Non-Hispanic White & $1(0.3 \%)$ \\
Non-Hispanic Black & $15(4.6 \%)$ \\
Asian & $19(5.8 \%)$ \\
Hispanic & $13(3.7 \%)$ \\
Other & $8(2.4 \%)$ \\
Chose not to respond & \\
\hline
\end{tabular}




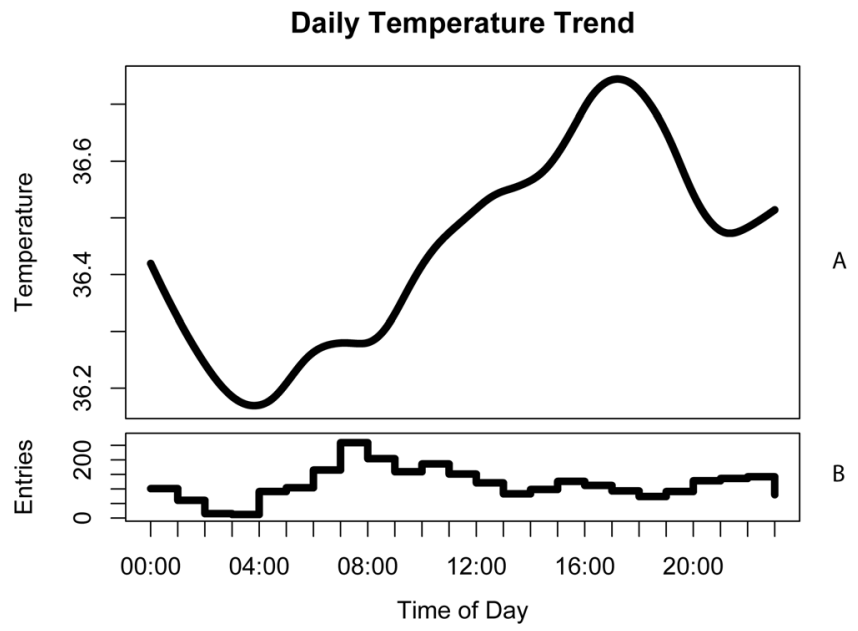

Fig. 1 (a) Average daily temperature and (b) number of temperature recordings at each hour. To assess temperature trends throughout the day, each entry was treated individually. To adjust for varying number of measurements per user, recordings were grouped into 15-

min intervals, and each user's average temperature over that

interval was treated as a single data point. These adjusted

temperature points were then plotted vs. recording time, and a smoothing cubic spline was applied to average over different users' recordings. Cubic spline interpolation was performed to generate curves sampled at regular intervals.

significant negative linear correlation between age and temperature $\left(r^{2}=0.032, p \sim 0\right)$.

\section{DISCUSSION}

By crowdsourcing temperatures from hundreds of adults, we found average oral temperatures to be $36.5^{\circ} \mathrm{C}$ and defined fever as $37.5^{\circ} \mathrm{C}$ or higher. Average temperatures varied significantly throughout the day and were affected by age and gender.

Our crowdsourced study supports previous research performed under controlled conditions: our mean normal temperature lies near the center of means from Sund-Levander $\left(36.2{ }^{\circ} \mathrm{C}\right)$ [3], Waalen $\left(36.3{ }^{\circ} \mathrm{C}\right)$ [1], and Mackowiak $\left(36.8^{\circ} \mathrm{C}\right)$ [2]. Prior classifications of "fever" utilized temperatures above $37.2^{\circ} \mathrm{C}$ at $6 \mathrm{am}$, or above $37.7^{\circ} \mathrm{C}$ at $6 \mathrm{pm}$, similar to our findings [2]. The gender and age differences we observed are similarly described in the literature [1-3].

Our results highlight the shortcomings of using a single value to define normal and febrile temperatures in patients of different demographics at different times of the day and emphasize the importance of a personalized approach to temperature, as we do for the other vital signs.

At the same time, we show that results from a smartphonebased, crowdsourced study conform with those of studies performed under controlled conditions. While previous work found ResearchKit data to be of good quality [5], ours is the first study that demonstrates patient-reported data from ResearchKit agrees with prior studies conducted under controlled conditions.

Limitations of our study include that we could not verify participants' data, temperatures were obtained with various thermometers, and only iPhone users were able to participate.

In summary, we recommend a personalized approach to temperature in the healthcare setting and provide strong evidence for the utility of ResearchKit for future medical research.

Acknowledgments: The authors would like to thank the participants who contributed their time and data to this study. Preliminary drafts of this study were previously presented in poster form:

- Feverprints: A Crowdsourcing Study of Temperature In Health And Disease. American College of Rheumatology Pediatric Rheumatology Symposium, Houston, TX May 18, 2017. Abstract 83.

- The Feverprints App: Crowdsourcing technology to study temperatures in health and disease. International Congress of Familial Mediterranean Fever and Systemic Autoinflammatory Diseases, Northern Cyprus, Turkish Republic. Saturday, May 6, 2017. Abstract 81.

Corresponding Author: Jonathan S. Hausmann, MD; Department of Rheumatology, Boston Children's Hospital, Boston, MA, USA (e-mail: jonathan.hausmann@childrens.harvard.edu).

\section{Compliance with Ethical Standards:}

Ethics: The Boston Children's Hospital Institutional Review Board approved this study.

Conflict of Interest: The authors declare that they do not have a conflict of interest.

\section{REFERENCES}

1. Waalen J, Buxbaum JN. Is Older Colder or Colder Older? The Association of Age With Body Temperature in 18,630 Individuals. The Journals of Gerontology Series A: Biological Sciences and Medical Sciences. 2011;66A(5):487-492.

2. Mackowiak PA, Wasserman SS, Levine MM. A critical appraisal of 98.6 degrees $\mathrm{F}$, the upper limit of the normal body temperature, and other legacies of Carl Reinhold August Wunderlich. JAMA. 1992;268(12):15781580.

3. Sund-Levander M, Forsberg C, Wahren LK. Normal oral, rectal, tympanic and axillary body temperature in adult men and women: a systematic literature review. Scand J Caring Sci. 2002;16(2):122-128.

4. Chamberlain JM, Terndrup TE, Alexander DT, et al. Determination of normal ear temperature with an infrared emission detection thermometer. Ann Emerg Med. 1995;25(1): 15-20.

5. Chan Y-FY, Wang P, Rogers L, et al (2017) The Asthma Mobile Health Study, a large-scale clinical observational study using ResearchKit. Nat Biotechnol 35:354-362. 